preliminary meeting in Brussels attended by nine scientists during October 1913. A second meeting was held during April 1914, and was attended by fourteen scientists from six European countries. After the First World War the Union was one of the first to be organized in 1919 under the general supervision of the International Research Council, which in 1931 was replaced by the International Council of Scientific Unions. The other three Unions were the International Astronomical Union, the Union of Geodesy and Geophysics and the Union of Pure and Applied Physics.

The first General Assembly of the International Scientific Radio Union was held in Brussels in 1922, and was followed by others in Washington (1927), Brussels (1928), Copenhagen (1931), London (1934) and Venice (1938). After an interval during the Second World War, the activities of the Union were resumed at the seventh general assembly held in Paris in 1946; and this was followed at two-year intervals by meetings in Stockholm, Zurich, Sydney and The Hague until 1954. On the last occasion it was decidod to change the interval between assemblies to three years; and the twelfth and thirteonth were held in Boulder and London in 1957 and 1960 respectively. The attendance on the latter occasion was about 830 , of whom nearly 450 were official delegates, and 150 were observers from the host country interested in various aspects of the scientific programme. There were also a small number of invited guests, and some 200 members of the families of delegates and observers.

The International Scientific Radio Union is one of the fifteen scientific bodies which now adhere to the International Council of Scientific Unions and it is in effect a federation of the national scientific academies in 28 countries throughout the world. The objectives of the Union are to promote and organize radio research requiring international co-operation, to encourage the development of such agreed methods of measurements as may be required for the investigation of any radio phenomona with particular reference to those associated with the Earth, its atmosphere and outer space. The influence of the Sun and of general and geophysical conditions on the radio phenomena has naturally required close collaboration between the four Unions referred to here. In more recent years, this collaboration has been extended to include the International Committee on Space Research (COSPAR) which was formed in 1958 and has recently held its fourth international symposium in Warsaw (May $1963)$.

To return to the forthcoming general assembly of the International Scientific Radio Union, the seiontific programme is being organized under the existing seven commissions, the titles and present chairmen of which are: (1) radio standards and measurements methods
(Dr. U. Adelsberger); (2) radio and troposphere (Mr. J. Voge); (3) ionospheric radio (Mr. J. A. Ratcliffe); (4) radio noise of terrestrial origin (Prof. R. A. Helliwell); (5) radio astronomy (Sir Bernard Lovell); (6) radio waves and circuits (Mr. J. Loela); (7) radioelectronics (Prof. W. G. Shepherd).

The wide range of scientific activities in various parts of the world in most, if not all, the aforementioned fields has made it necessary to restrict the scope of the items selected for discussion at each of the sessions which will be available to the commissions. Accordingly, each chairman has formulated the subjects to be discussed by his commission and has invited some well-known authorities to prepare introductory papers for presentation at Tokyo. These papers, together with a summary of the main features of the discussion thereon, will be published in the Proceedings of the general assembly. In accordance with past practice, no uninvited papers will be considered for acceptance. As some of the subjects selected for discussion are of common interest to more than one commission, arrangements have been made in the programme for joint meetings and also for meetings of the commissions with other committees of the Union such as that on space radio research or with the International Committee on Geophysics. The latter body, incidentally, has replaced the former committee which organized the co-operative scientific work during the International Geophysical Year of 1957-58 and afterwards, and it has recently been actively engaged in formulating the corresponding programme for IQSY, the International Year of the Quiet Sun (1964-65).

At the general assembly in London in 1960, representatives from the International Scientific Radio Union were appointed to its parent body-ICSU-as well as to various specialist committees in which the Union is associated with the interests of other unions or committees in such subjects as the ionosphere, radio meteorology, solar and terrestrial relationships, space researeh and the allocation of radio frequencies for radio astronomy and space science. In this way, full collaboration is maintained between scientists in all parts of the world engaged in research in adjacent fields concerned with the Earth and its atmosphere, the Sun, the planets and outer space. Meotings of these committees will be called as may be appropriate during the general assembly, taking advantage of the presence in Tokyo of the various interested scientists.

During the Assembly various formal receptions are being arranged by the Japanese Committee, and some visits of technical interest will be offered to the visitors. A special programme for ladies has also been distributed. After the assembly, a four-day tour is available to Kyoto and Nara, towns which are of historic interest because they were former capitals of Japan.

\title{
MULTIPLE MOLECULAR FORMS OF ENZYMES AND THEIR USE IN CLINICAL DIAGNOSIS
}

\begin{abstract}
A SYMPOSIUM on "Multiple Molecular Forms of A Enzymes" organized by the University of Ghent in collaboration with the Belgian Society for Clinical Chemistry, was held in Ghent on April 27. It was the first of its kind in Europe, and the interest it arose can be judged from the fact that several weeks before the deadline for registration, the limiting number of 150 participants had already been reached. Representatives from most west European countries were included among the speakers and also several from the United States.

The meeting was concerned with the structure of isoenzymes and with their clinical uses. As to the first, E. Appella (Centre de Chimie Macromoléculaire, Strasbourg) presented data defining the physical properties of lactic
\end{abstract}

dehydrogenase 1 (LDH1) and LDH5 (beef tissue) and their amino-acid composition. All available evidence tends to support the hypothesis formulated by the author together with Markert that LDHI is composed of four identical sub-units, while LDH5 is composed of four identical sub-units of another type; LDH2, LDH3 and LDH4 correspond to combinations of each of these sub-units into groups of four. These hybrid forms can be produced in vitro: following dissociation into sub-units of pure LDHI and LDH5 molecules in a medium of high ionic strength, randomized re-association occurs on removal of the sodium chloride.

M. D. Poulik (Child Research Center, Detroit) took ceruloplasmin as an example of a second class of isoenzymes 
- the polymer type. He advocated the use of electrophoretic media differentiating between size of the molecules; experiments with such dissociating substances as urea and SH-compounds also give useful information concerning the number and nature of the sub-units. $K$. Van Asperen (Laboratory for Insecticide Research, Wageningen) stressed the importance of genetic investigations in drawing up the isoenzyme concept. He pointed out that from his work on esterases in the house-fly it is clear that a third class of isoenzymes occurs where the difference is one in primary structure. In support of this view, M. Rabaey and H. Gysels (Department of Ophthalmology and Zoology, University of Ghent) described the multiplicity of myoglobins in vertebrates. Myoglobins can be considered isoenzymes since they all have peroxidase activity.

Several speakers surveyed the method for isoenzyme separation which they developed. H. J. Van der Helm (Provinciaal Ziekenhuis, Santpoort) discussed electrophoretic methods. He made interesting comments on specific problems that are encountered when a conventional histochemical technique is applied to the detection of enzyme activity in electrophoresis slabs. Here, one is more concerned with quantitative aspects than with precise localization. Eluting effects should be reduced by choosing a thick layer for electrophoresis, but rapid contact with the reagents is obtained if thin layers are used. Both requirements can be met in an agar medium. G. A. Whyley (University College, London) used cellulose acetate electrophoresis followed by elution of the segments. H. Barnett (South London Hospital for Women, London) favoured tho tetrazolium procedure for direct staining of the cellulose acetate strips. She described two types of 'nothing' reactions. The first occurs in the presence of tetrazolium and phenazine methosulphate and results from reduction of the tetrazolium salt by - SH groups of proteins. The second requires in addition the presence of NAD and secms to be enzymatic, but occurs without any addition of substrate.

Column chromatography on DEAE cellulose was utilized by S.-T. Walter (Medizinische Universitäts-Klinik, Heidelberg) for separation of LDH isoenzymes and by B. Schobel (Medizinische Universitäts-Klinik, Vienna) for isolation of leucine aminopeptidase (LAP) isoenzymes. Walter also used a simple batch procedure, developed together with Hess for detecting LDH5 in human serum. The procedure is rapid but gives only a 'yes' or 'no' answer.

J. H. Wilkinson (Westminster Medical School, London) commented on a new procedure for assay of LDH isoenzymes. He found, together with Rosalki, that LDHl has a much higher activity against $\alpha$-ketobutyrate than LDH5. Thus an assay of LDH activity is made with each of these substrates and an index established which reflects changes in the isoenzyme pattern. The procedure proves especially valuable in the follow-up of myocardial infarction.

Another indirect procedure depending on selective thermal inactivation of LDH5 was described by $\mathbf{H}$. Wust (Medizinische Universitäts-Klinik, Erlangen). The serum is heated for $30 \mathrm{~min}$ at $56^{\circ} \mathrm{C}$. If more than 40 per cent of the activity disappears this indicates the presence of LDH5. However, several environmental factors, especially protein concentration and $p \mathrm{H}$, tend to render this test less reliable.

Clinical applications were introduced by E. S. Vesell (Rockefeller Institute, New York), who warned against overestimating the specific diagnostic value of LDH isoenzyme determination. Similar patterns may be observed in sera from patients with different, unrelated disease. An increase in serum LDH5 is found not only in liver injury but also in some cases of acute arthritis and of dermatomyositis. In particular, shock, both hæmorrhagic and endotoxic, may liberate LDH from various tissues and thus distort the pattern from that expected for an uncomplicated disease.
H. A. Zondag (St. Elizabeth's Gasthuis, Haarlem) summarized the experience he collected from 4,000 determinations of the LDH isoenzyme pattern (agar-gel and 'Nitro-BT' method) in serum and other body fluids. He distinguished three main patterns: that of acute myocardial infarction (high LDHI), that of acute hepatic necrosis (high LDH5) and that of malignancy (high LDH2, $3,4)$. The pattern of acute myocardial infarction has the highest clinical significance. Samples should not be stored in the frozen state since LDH5 may then be inactivated. U. C. Dubach (Medizinische UniversitätsKlinik, Basle) used thermal inactivation at two temperatures for differentiation between LDH isoenzymes. The method proved especially useful for follow-up of myocardial infarction, also for the diagnosis of pulmonary infarction and of primary myopathies. In the diagnosis of liver diseases results were less encouraging. L. J. Denis (Medical College of Virginia, Richmond) used agar-gel electrophoresis combined with the tetrazolium method for LDH analysis in malignancy. In cases of prostatic carcinoma in relapse an increase of serum LDH5 is regularly found. S. B. Rosalki (Kingston Hospital, Kingston upon Thames) investigated the isoenzymes of alkaline phosphatase, LDH and leucine aminopeptidase (LAP) in pregnancy. L. Pagliaro (Clinica Medica Generale, Palermo) used the Rosalki-Wilkinson test and obtained encouraging results. In muscular dystrophy the index pointed to an unexpected increase of $\mathrm{LDH}$. In the discussion it was made clear that this shift is to be explained by the modification in the LDH pattern of dystrophic muscle as described by Wieme and Herpol using agar-gel electrophoresis. G. Schapira (Hôpital des Enfants-Malades, Paris) reported on the changes in the LDH pattern of dystrophic muscle as revealed by starch-gel electrophoresis. The pattern recalls that of foetal muscle. This suggests the occurrence of an arrest, in the development of certain muscle proteins. J. Herpol (Kinderkliniek, University of Ghent) studied 150 normal children for the LDH serum pattern. The distribution was found to be similar to that in adults. In some cases a value highor than 75 per cent was found for LDHI; total LDH activity was then generally low.

Several other types of isoenzymes were also discussed for their clinical value. Malate dehydrogenase (MDH) was studied by M. Van Sande (Instituut voor Tropische Geneeskunde, Antwerpen) and proved of little diagnostic value. Despite separation into some nine fractions, all tissues tend to oxhibit the same pattern. Leucine aminopeptidase was investigated by F. W. Wewalka (Medizinische Universitäts-Klinik, Vienna). Modifications in the serum pattern (starch-gel electrophoresis) mainly concern the appearance of new fractions. In liver disease modifications appear in the slow area. In pregnancy a new fraction of intermediate mobility is found. No direct relation with corresponding tissue fractions is manifest. This point was confirmed by R. Delcourt (Institut Médical, Ixelles), who also directed attention to the possible interference from inhibitors. A. J. Van Triet (Antoni van Leeuwenhoekhuis, Amsterdam) studied LAP isoenzymes in urine and found that in reticulosis a fraction is present that has a somewhat lower mobility than that usually found.

Alkaline phosphatases seem to constitute a promising field for isoenzyme analysis. B. N. Jensen (Psychiatric Institute, Aarhus) found three alkaline phosphatases in serum (electrophoresis on a polyvinyl chloride block). The ratio between the slowest and the intermediate form constitutes an index that serves to separate patients with liver disease (low index) from those with bone involvement (high index). W. G. Haije (Radiotherapeutisch Instituut, Rotterdam) used agar-gel electrophoresis for detecting physiological or pathological bone formation (increase of slowest) and for detecting liver disease (increase of most rapid fraction). The method seems especially interesting for detection of liver metastases. 
Those present at the symposium agreed that: (1) The isoenzyme concept should be kept broad with a definition that could be given as follows: "different proteins with similar enzymatic activity". (2) Determination of LDH iso- enzymes already now occupies a useful place in the clinical laboratory. (3) Direct histochemical procedures are preferable, but among indirect methods the Rosalki-Wilkinson test deserves special attention.
R. J. WIEME

\section{THE EAST AFRICAN ACADEMY}

\section{FIRST SYMPOSIUM AND INAUGURAL ANNUAL GENERAL MEETING}

$\mathrm{N}^{\mathrm{N}}$ EARLY three years since the idea was first put forward, the East African Academy came into being February 1963. Four months later, during June 14-17, the first symposium and annual general meeting was held at which more than 120 scholars, including eight delegates (representing the Royal Society of London, the Japanese Academy of Sciences, the Weizmann Institute of Science, and the U.S. National Academy of Sciences) attended. Messages of greetings and good wishes, apart from the aforementioned institutions, came from the U.S.S.R. Academy of Sciences, the Academia Sinica, the American Academy of Arts and Sciences, and from individuals and local organizations.

In many ways the East African Academy shows interesting characteristics. It is a regional, rather than a narrowly national, academy-covering the four East African countries of Kenya, Tanganyika, Uganda, and Zanzibar; it takes all departments of learning within its purview; apart from the usual aims of national academies, namely, the promotion of learning and the dissemination of knowledge, the Academy will take as its first-priority objective "to encourage scientific, technological and other advanced training within East Africa and to find ways and means for such training elsewhere"; and, because the Academy regards research by its members as one of its most important activities, it has already appointed a powerful four-man committee to be responsible for devising and taking immediate action on a policy for sponsoring research programmes, approving other research projects, selecting candidates for research fellowships, and handling research funds.

Two whole days were devoted to the symposium meetings, at which twenty-nine papers were read representing general themes (5), physical and chemical sciences (6), biological sciences (10), and arts and social sciences (8). The opening address was delivered by Dr. H. H. Storey, as a member of the Academy, on "East African Research on Plant Virus Diseases". After dealing with the history of virus research for the past seventy years briefly, he emphasized the contribution of East African work to virology by reviewing the investigation on cassava mosaic, groundnut rosettc, and maize streak-all three being entirely African plant virus diseases. Finally, he demonstrated how the work on the obligate relationship between arthropod vector and virus has contributed to our fundamental knowledge of the vector-parasite association.

Prof. L. C. Beadle ("Inland Waters of East Africa as a Field for Fundamental and Applied Research") considered that East Africa presents particular problems because of its geological history, and the mode of origin of its lakes since the Miocene has provided a great stimulus for the evolution of new species of animals, for example, 400-500 species of fish are endemic. Factors which determine breeding seasons are more problematical in tropical environment: for example, there is a correlation with the onset of rain, and there seems to be an internal hormonal rhythm. The lake bottom is highly reducing, and it is suggested that it might be possible to pump up deep water in order to increase the circulation of organic matter (as the Belgians are already attempting in regard to Lake Kivu).
Glynn Isaac ("Olorgesailie: a Study of the Natural History of a Pleistocene Lake Basin and an Early Stage in Human Cultural History") affirmed that East Africa, particularly during the past thirty million years, is comparatively well endowed with basins containing deposit: of the largest unbroken fossil record, later made available by tectonic disturbances followed by erosion. East Africa. therefore, appears to have been a centre of cultural and physical evolution. Olorgesailie Lake Basin in the Kenya section of the Rift Valley offers a good opportunity for such Quaternary research: he outlined the geological circumstances of the basin, and attempted a preliminary reconstruction of the environment of the basin 100,000 200,000 years ago, and of man's (supposed) activities in relation to it.

J. Gitau ("Importance of Soil Fertility and Fertilizer Use in Kenya, with Special Reference to African Farmers") stated that farmyard manure has been used from early times, but that this is increasingly becoming difficult in Kenya owing to the limitation of available land to peasant farmers. Hence, the use of artificial fertilizers offered a solution. This, however, raised the vital question of cost : and it was suggested that, as one of their important services, co-operatives should shoulder the responsibility of buying and distributing fertilizers.

Dr. Z. Subarsky ("Operation Ecology") described how a private committee was recently formed to rectify a state of affairs in biology teaching in East African schools in which the syllabuses, text-books, methods, and some. times even type specimens for practical classes are imported from abroad. The committee is making an ecological classification in the form of a series of maps (physical, geological, climatic, and vegetational) on which schools will be marked. This procedure will facilitate selection of type specimens for particular topics in the syllabuses.

\section{Physical and Chemical Sciences}

L. A. J. Williams ("Geology of the Narok District of Masailand") described the mapping in reconnaissance style of this area, and included a summary of the exposed geological successions, maximum thicknesses, and some of the principal tectonic and physiographic events in the area. The talk was followed by that of Miss M. Lindley ("Notes on the Hydrology of the Mara-Narok Area"), who considered the relatively meagre hydrological records available of Masai areas. From these, she made the following tentative conclusions: the 49 -year (1913-62) mean rainfall is 28.29 in., the $1933-49$ period was one of generally below-average rainfall $(24 \cdot 0 \mathrm{in.})$, the $1950-53$ poriod one of varying rainfall, and the 1954-62 period was a wet one (27 per cent above the mean). November-May is the wet period, but no month is free from the risk of drought; on the other hand, the pattern of evaporation through the year fluctuates much loss than that of rainfall She came to the conclusion that the average rainfall left no excess moisture for streamflow or replenishment of water stores. P. H. Temple ("Raised Features along the Southern Shoreline of Lake Victoria") noted the presence of extensive deposits of lacustrine sands and clays, now considerably above the present level of the Lake; and he offered speculations as to their significance. 